\title{
Professional Correspondence
}

\author{
F. Fritsch
}

February 6, 1997

This is an informal report intended primarily for internal or limited external distribution. The opinions and conclusions stated are those of the author and may or may not be those of the Laboratory.

Wnrk performed under the auspices of the U.S. Department of Energy by the Lawrence Livermore National Laboratory under Contract W-7405-Eng-48. 


\section{DISCLAIMER}

This document was prepared as an account of work sponsored by an agency of the United States Government. Neither the United States Government nor the University of California nor any of their employees, makes any warranty, express or implied, or assumes any legal liability or responsibility for the accuracy, completeness, or usefulness of any information, apparatus, product, or process disclosed, or represents that its use would not infringe privately owned rights. Reference herein to any specific commercial product, process, or service by trade name, trademark, manufacturer, or otherwise, does not necessarily constitute or imply its endorsement, recommendation, or favoring by the United States Government or the University of California. The views and opinions of authors expressed herein do not necessarily state or reflect those of the United States Government or the University of California, and shall not be used for advertising or product endorsement purposes.

This report has been reproduced directly from the best available copy.

Available to DOE and DOE contractors from the Office of Scientific and Technical Information

P.O. Box 62, Oak Ridge, TN 37831

Prices available from (615) 576-8401, FTS 626-8401

Available to the public from the

National Technical Information Service

U.S. Department of Commerce

5285 Port Royal Rd.,

Springfield, VA 22161 
4 February 1997

Hiroshi Akima

U. S. Department of Commerce

NTIA / ITS

325 Broadway

Boulder, CO 80303

Dear Dr. Akima:

It has been a long time since we have corresponded about interpolation methods. Since then there have been a lot of changes in the Computing Directorate here at LLNL and I haven't had a chance to keep up with the literature until recently.

This letter is prompted by your article entitled, "Note on Local Methods of Univariate Interpolation," which appeared in the April 1996 issue of the SIGNUM Newsletter. In that article you compared various univariate methods and conclude that your Algorithm 697 is probably the best. Because I had let my subscription to ACM Trans. Math. Software lapse for a few years, I was not familiar with Algorithm 697, so the first thing I did was go to the library and get a copy of your article.

I notice that our routine PCHIC, which you refer to as "the F-C-B method", is mentioned briefly in the TOMS article, but does not appear in any of the comparisons in either paper. (PCHIC can be obtained via Netlib, http://www.netlib.org/ or http://netlib.bell-labs.com/.) The purpose of these notes is to provide information about PCHIC comparable to what you gave in the newsletter article.

Since neither you nor Ellis and McLain tell precisely how the "average deviation from the original function" is computed, I first implemented the Ellis-McLain algorithm (Algorithm 514) and attempted to reproduce the numbers given for the five analytic functions in their paper. I found that using 1000 uniformly spaced subintervals (1001 uniformly spaced evaluation points, including the endpoints) gave comparable results. I also did the computations for Algorithm 697 (cubic method only) and two PCHIC options, one using the default endpoints (PCHIC0) and the other matching the endpoint derivatives of the exact functions (PCHIC1). All PCHIC runs used SWITCH $=-1$. The results $\left(x 10^{6}\right)$ are as follows:

\begin{tabular}{crrrr} 
& \multicolumn{4}{c}{ Method } \\
\cline { 2 - 5 } Function & Alg. 514 & Alg. 697 & PCHIC0 & PCHIC1 \\
\hline$x^{3}$ & 0 & 0 & 15915 & 13562 \\
$x^{4}$ & 6413 & 5591 & 77824 & 51589 \\
$\exp \left(-x^{2} / 2\right)$ & 76 & 122 & 843 & 840 \\
$\tanh x$ & 139 & 132 & 540 & 527 \\
$\sin x$ & 179 & 135 & 1690 & 1228
\end{tabular}

I presume that the differences between some of these results and those in the newsletter article are due to the fact that I did not use exactly the same evaluation points as you. 
Since there is second derivative discontinuity only at the interior data points, I took the phrase "average discontinuity of the second derivative at data points" to be the sum of the absolute values of the second derivative jumps (which can be computed exactly) at the 16 interior points, divided by 16 . The results $\left(\times 10^{4}\right)$ are as follows:

\begin{tabular}{crrrr} 
& \multicolumn{4}{c}{ Method } \\
\cline { 2 - 5 } Function & Alg. 514 & Alg. 697 & PCHICO & PCHICl \\
\hline$x^{3}$ & 0 & 0 & 73587 & 73649 \\
$x^{4}$ & 5766 & 32771 & 255814 & 244763 \\
$\exp \left(-x^{2} / 2\right)$ & 268 & 833 & 8620 & 8506 \\
$\tanh x$ & 469 & 931 & 5494 & 5464 \\
$\sin x$ & 198 & 295 & 10485 & 10800
\end{tabular}

I do not have an explanation for the differences between the numbers for Alg. 514 and 697 and those in your article. Nonetheless, these seem to bear out your claims for Alg. 697 when interpolating data from analytic functions, although they show PCHIC to be comparable to Alg. 433.

I am not sure why you included graphical results for any of these examples in you article, since all methods give comparable-appearing curves. In fact, when I superimposed the curves for Alg. 697 and those for PCHIC they appeared to be identical.

I also computed the PCHICO results for all of the sample data sets in your Algorithm 697 TOMS article, and enclose plots comparing them to Alg. 514 and Alg. 697. In order to investigate strange behavior of PCHIC near $x=1$, I have also included plots for two modifications of the $\sin (\pi x)$ data: modification $A$ includes data for $x=0.75$ and $x=1.25$; mod. B instead includes data for $x=0.60$ and $x=1.40$.

I conclude from these results that Algorthm 697 is superior to PCHIC on sparse analytic data, PCHIC gives more "visually pleasing" results on all the Akima data sets, and the two are comparable on "reasonable" data sets, where sufficient data are given to represent the shape of the underlying phenomenon. The appearance of some of these curves indicates that some work is needed for PCHIC to produce visually pleasing results on nonmonotone data.

Sincerely,

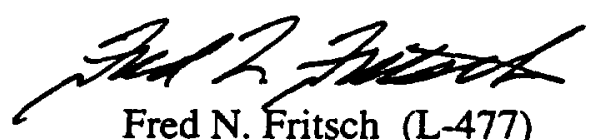

Fred N. Fritsch (L-477)

Computer Applications Organization

LCPD / ICF Group 
Fig. 1

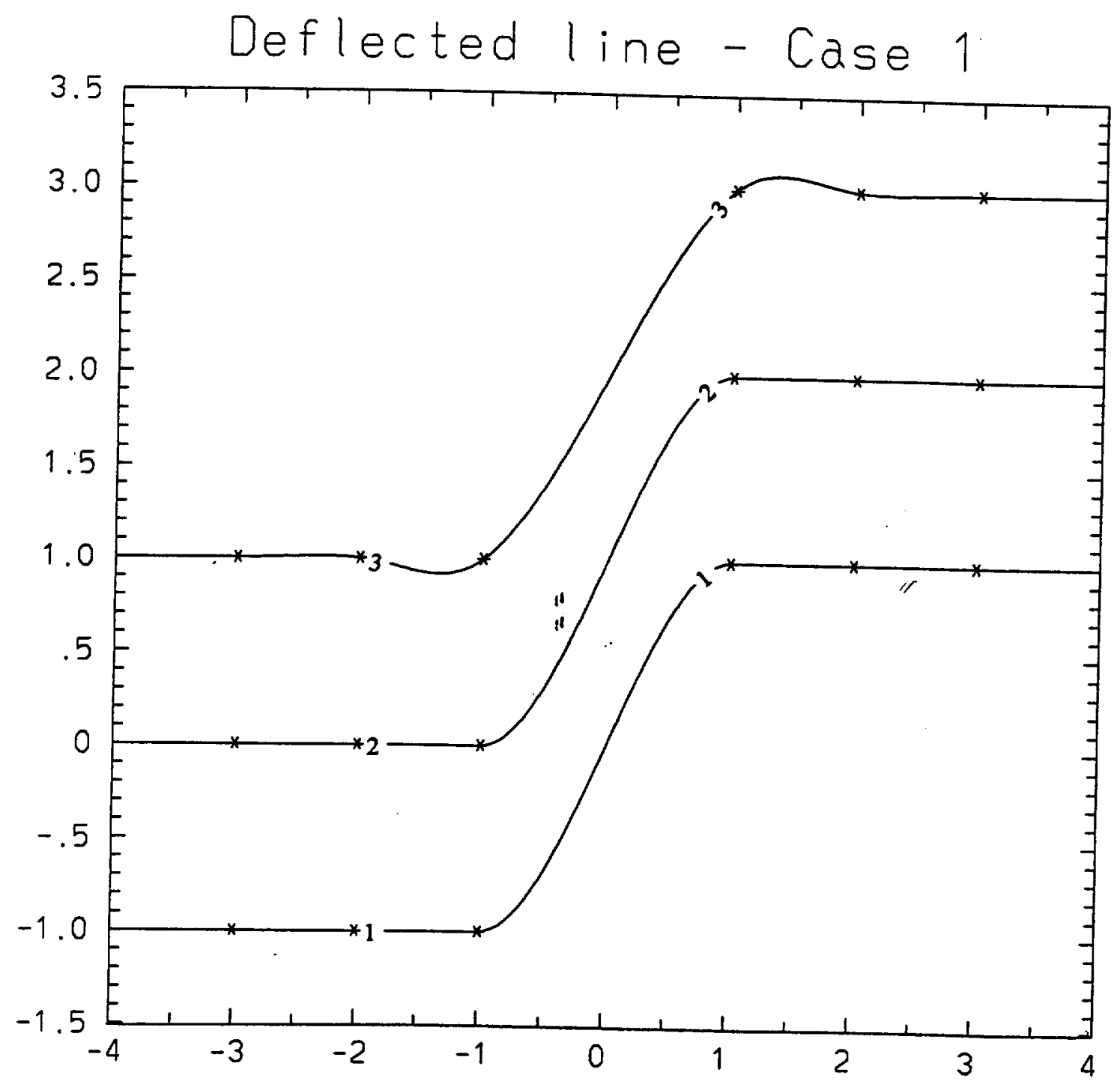

1: PCHIC (default B.C.. SWITCH $=-1$ )

2: Algorithm 697

3: Algorithm 514 
Fig. 2

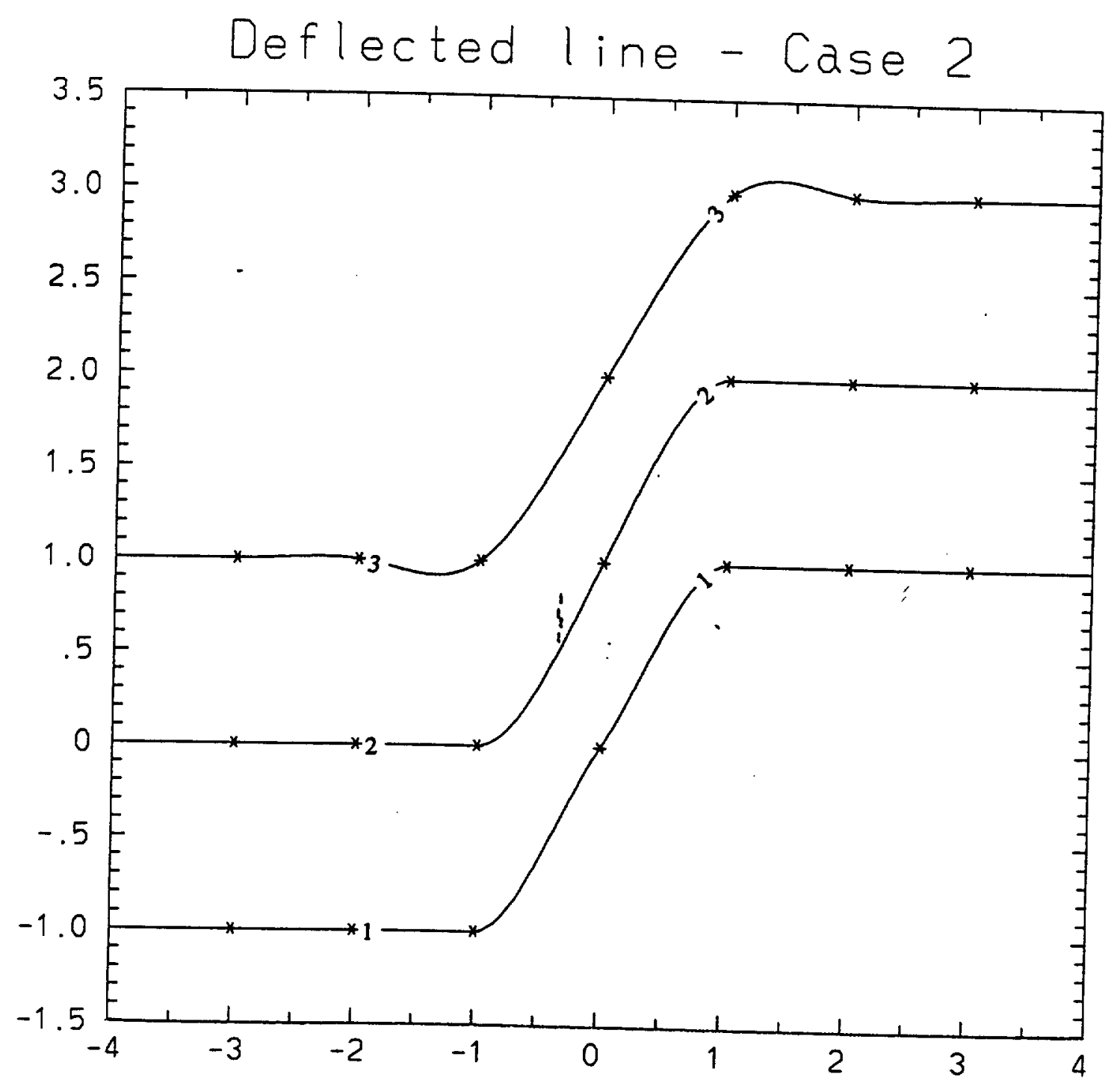

1: PCHIC (default B.C., SWITCH=-1)

2: Algorithm 697

3: Algorithm 514 
Fig. 3

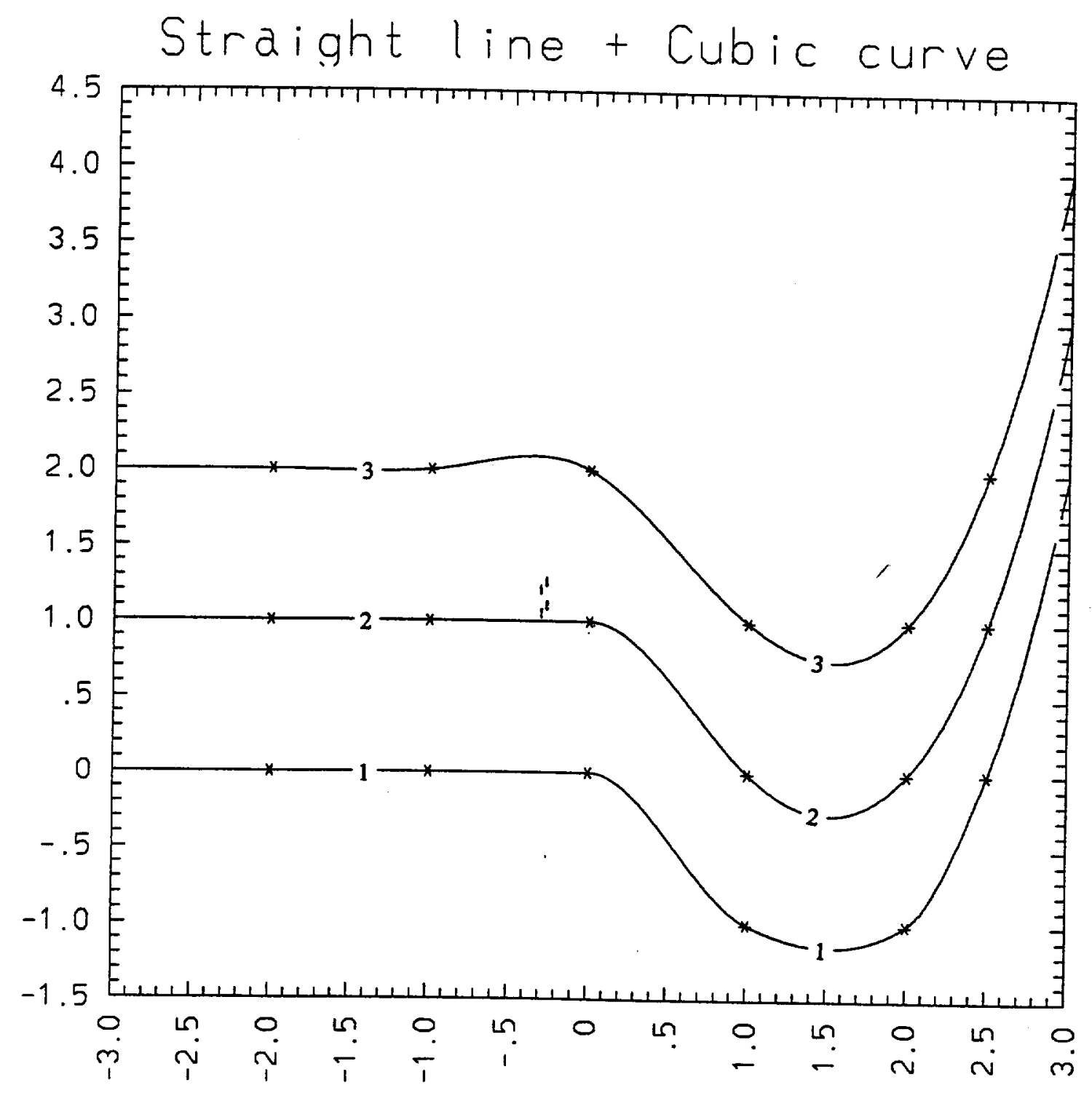

1: PCHIC (default B.C., SWITCH=-1)

2: Algorithm 697

3: Algorithm 514 
Fig. 4

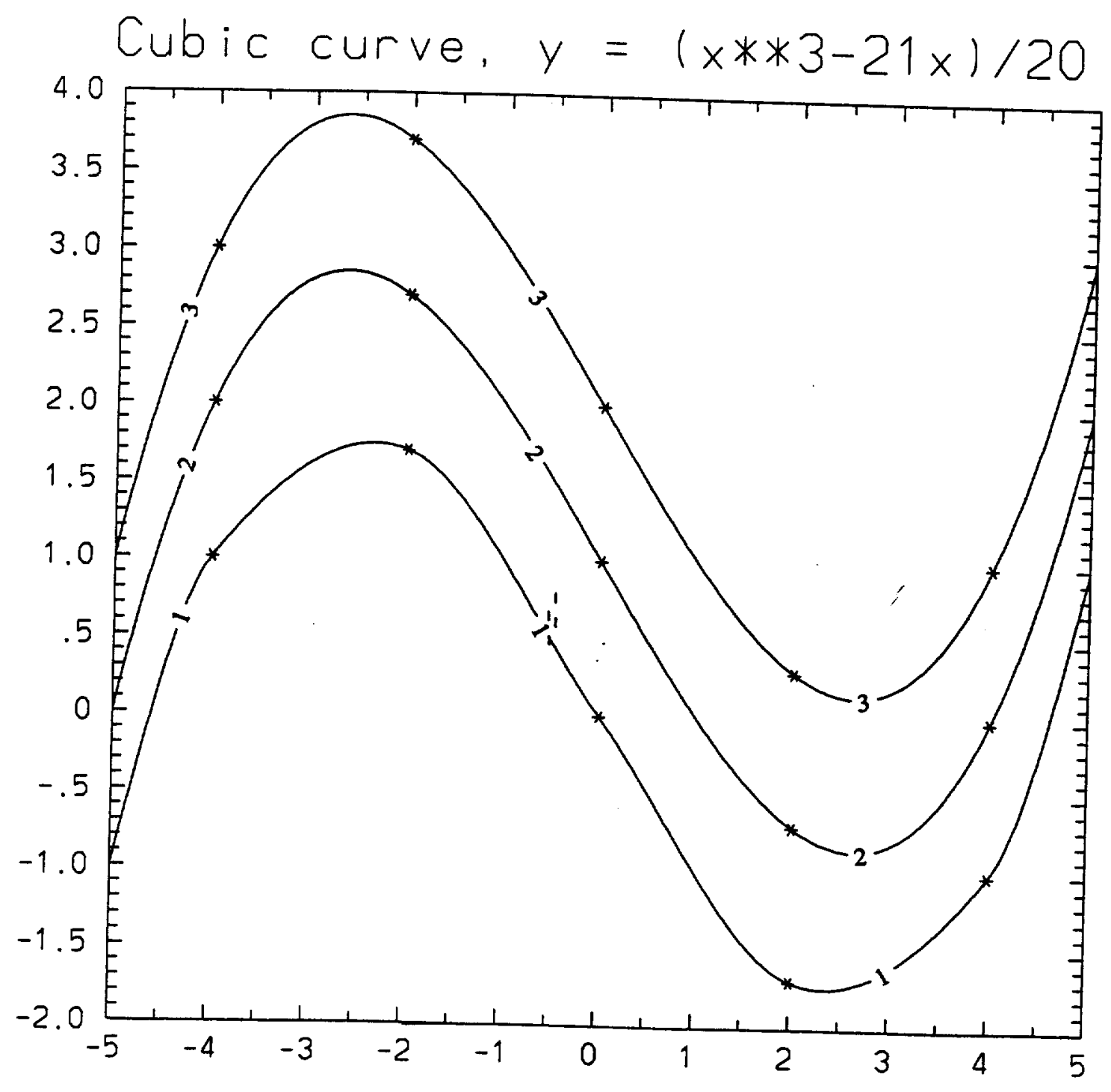

1: PCHIC (default B.C.. SWITCH=-1)

2: Algorithm 697

3: Algorithm 514 
Fig. 5

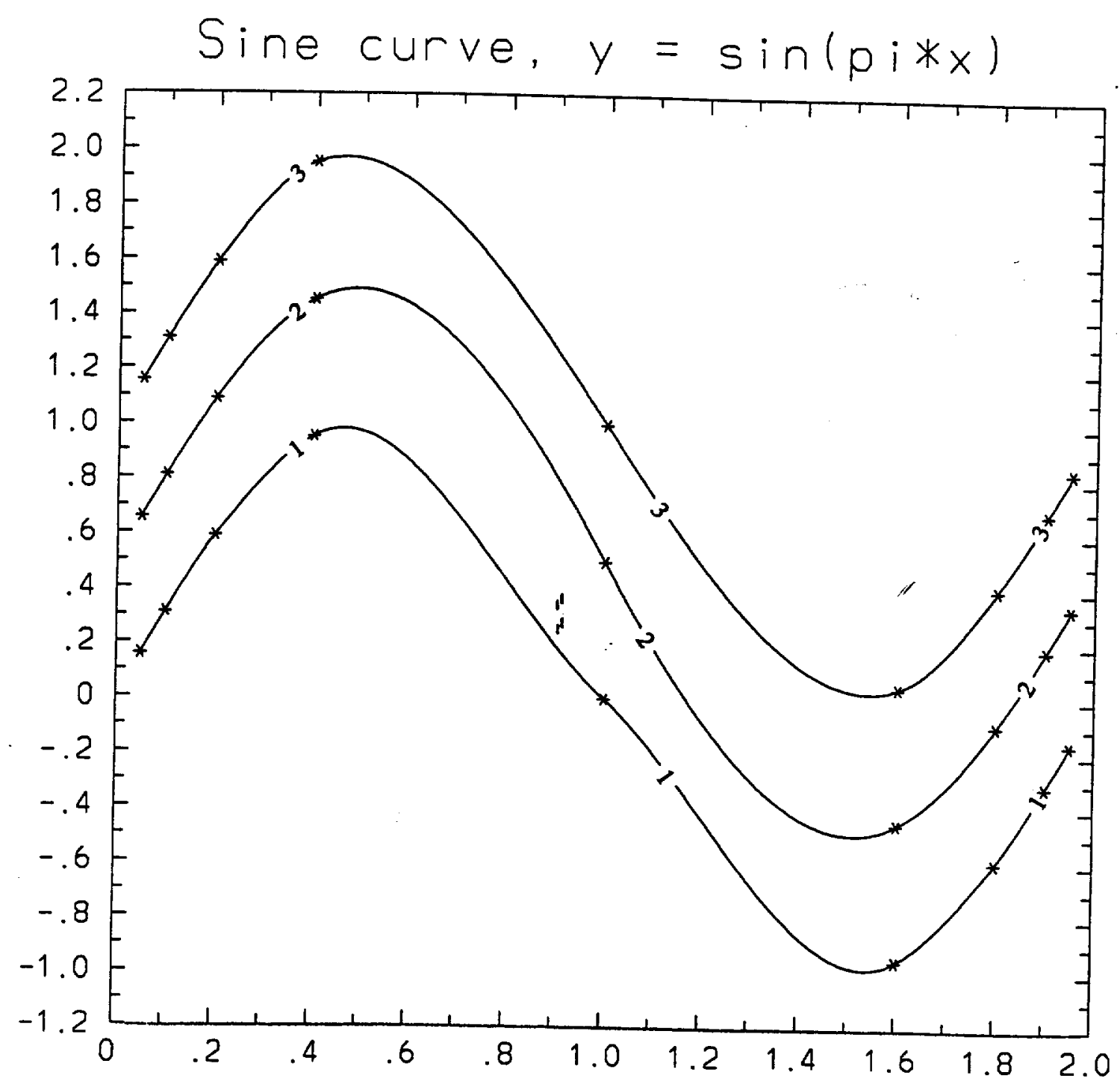

1: PCHIC (default B.C., SWITCH=-1)

2: Algorithm 697

3: Algorithm 514 
Fig. $5 a$

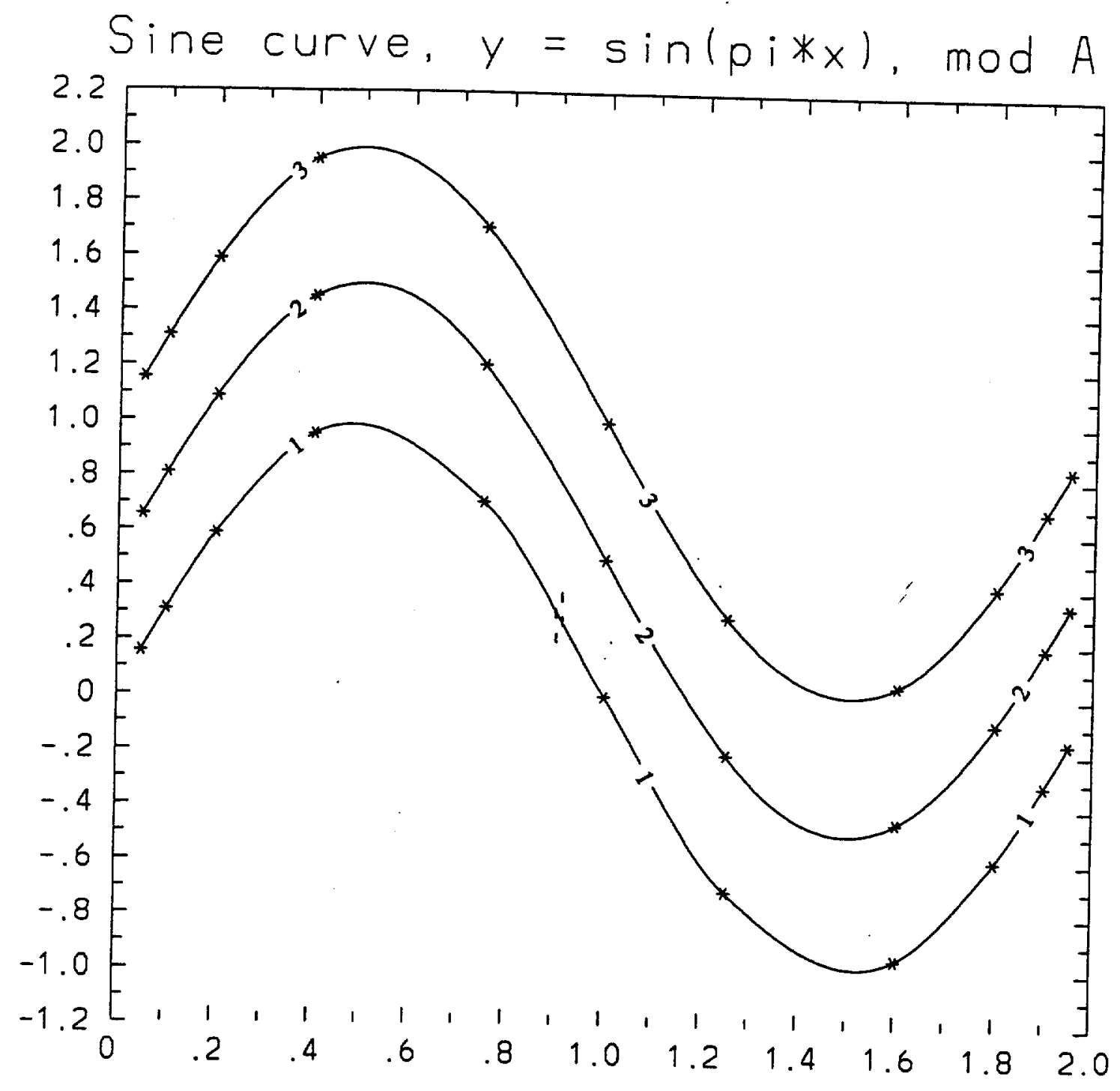

1: PCHIC (default B.C.. SWITCH $=-1$ )

2: Algor ithm 697

3: Algorithm 514 
Fig. $5 b$

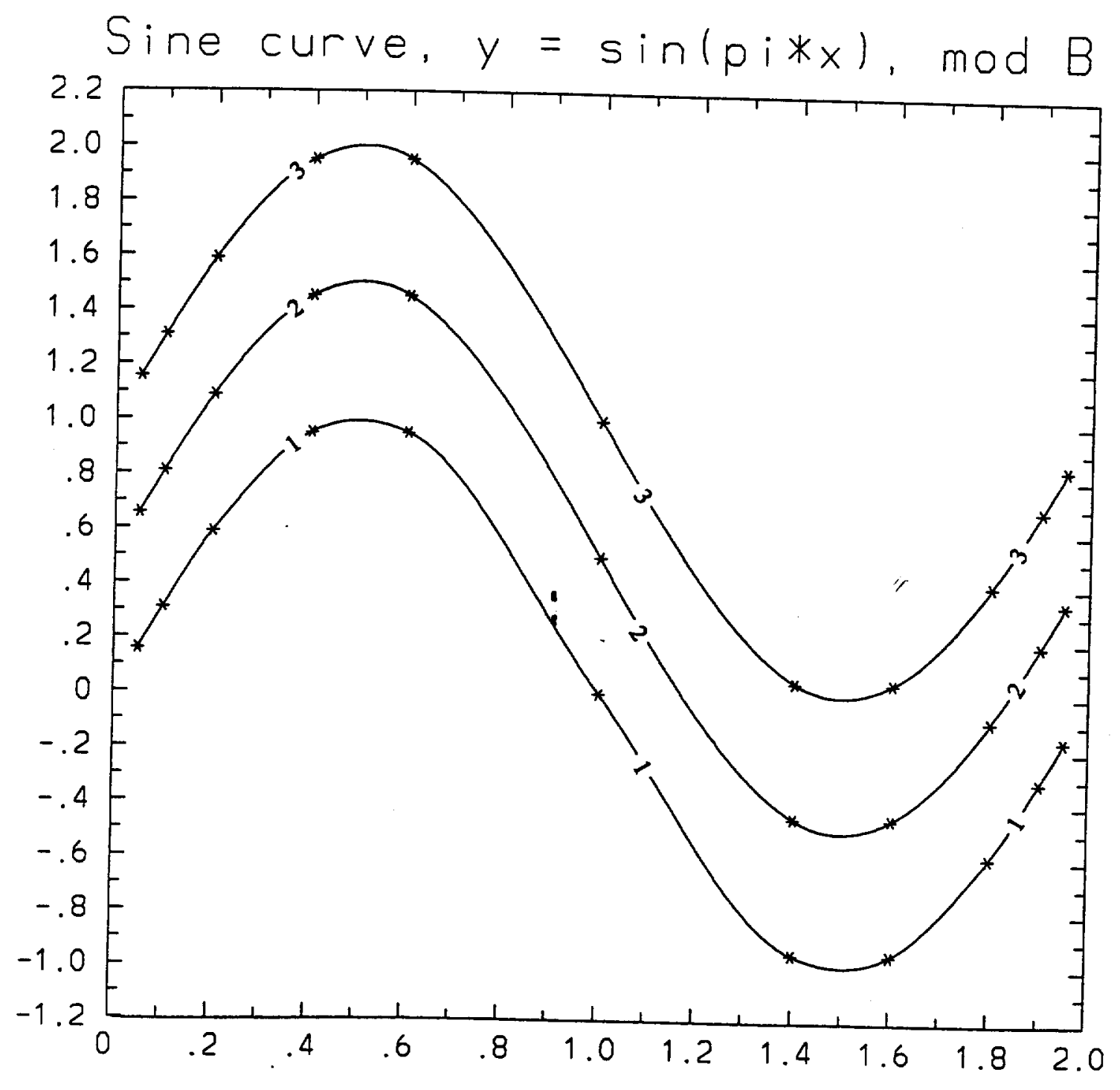

1: PCHIC (default B.C., SWITCH=-1)

2: Algorithm 697

3: Algorithm 514 
Fig. 6

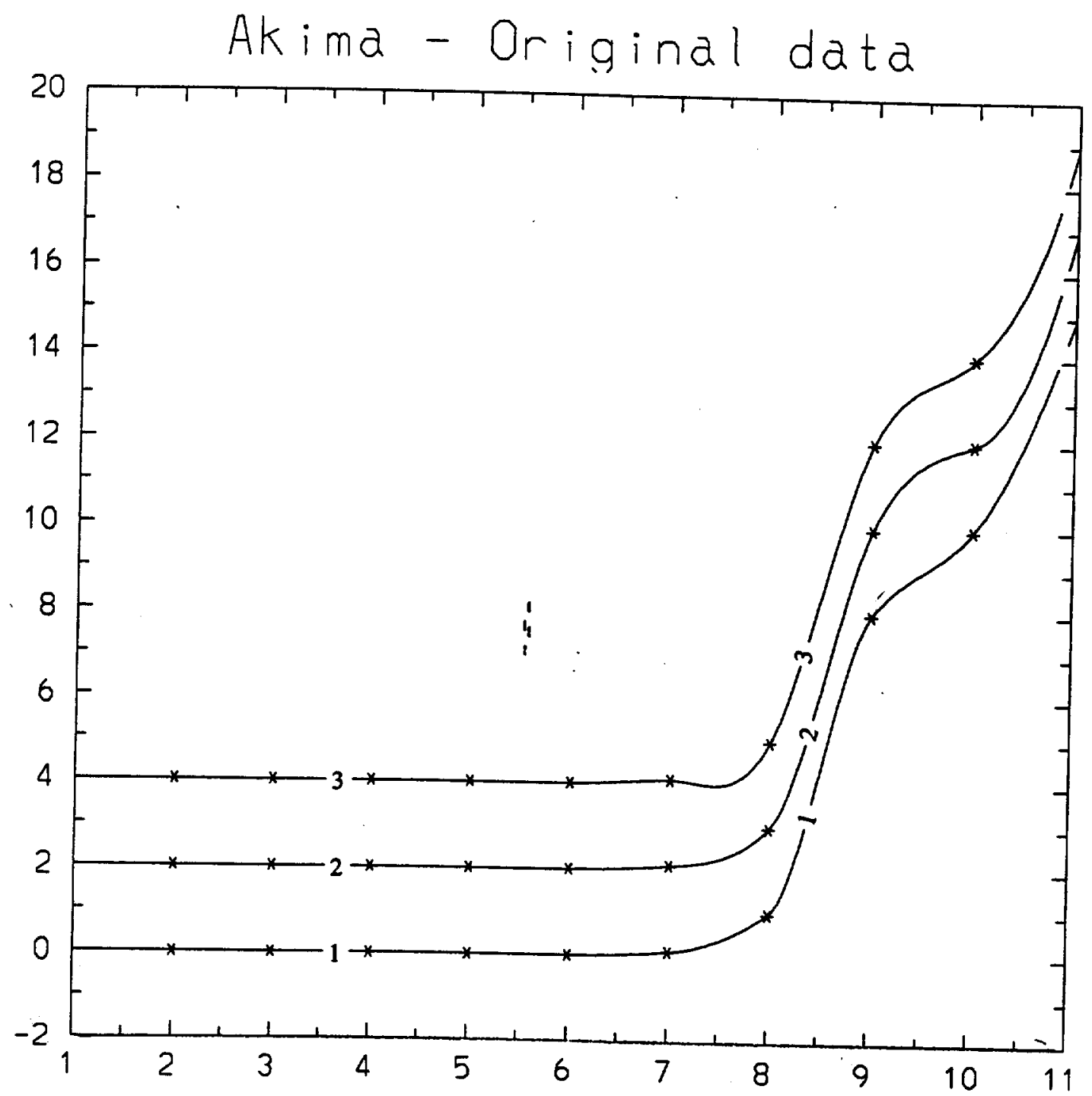

1: PCHIC (default B.C., SWITCH=-1)

2: Algorithm 697

3: Algorithm 514 
Fig. 7

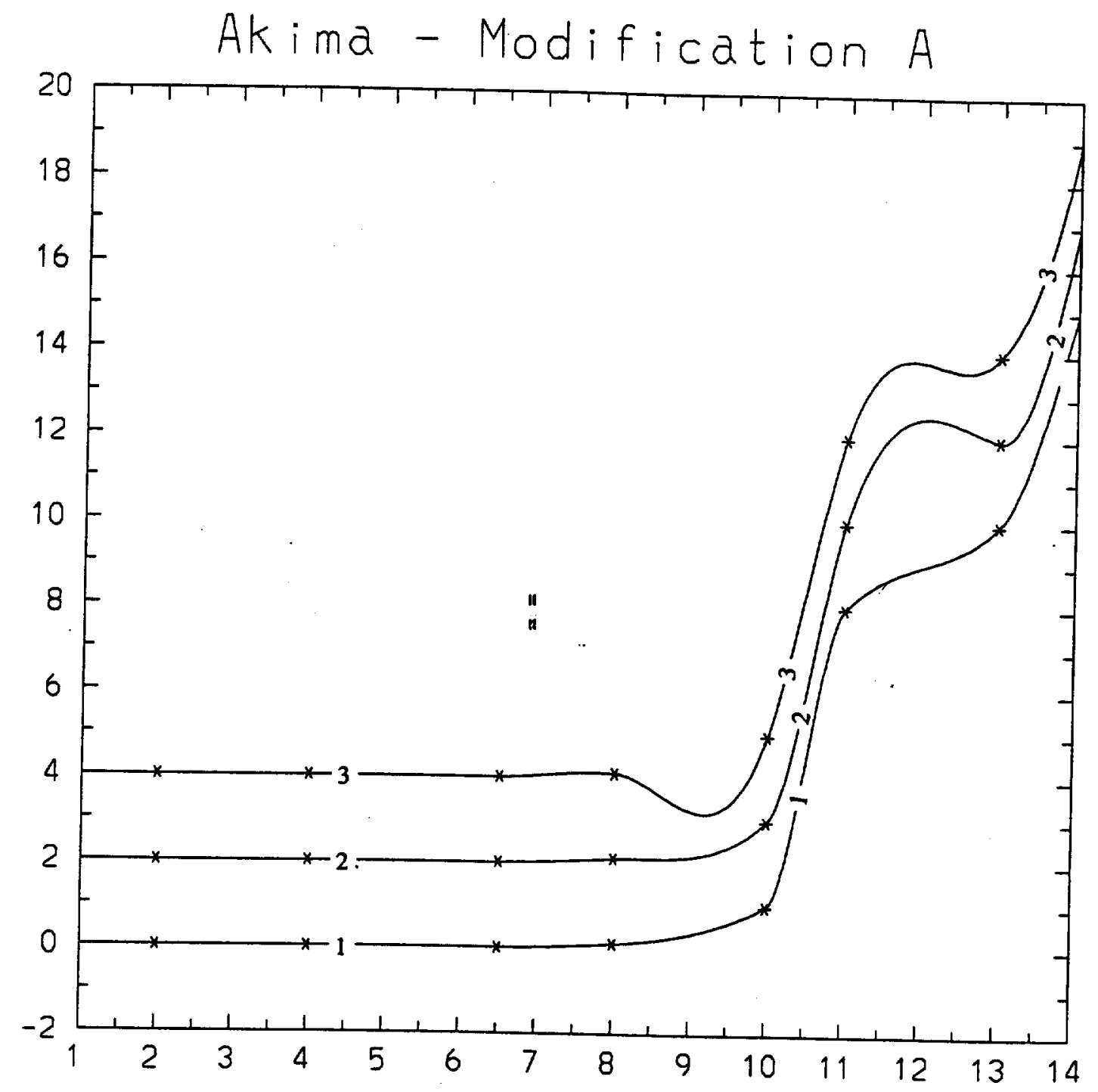

1: PCHIC (default B.C.. SWITCH $=-1$ )

2: Algorithm 697

3: Algor ithm 514 
Fig. 8

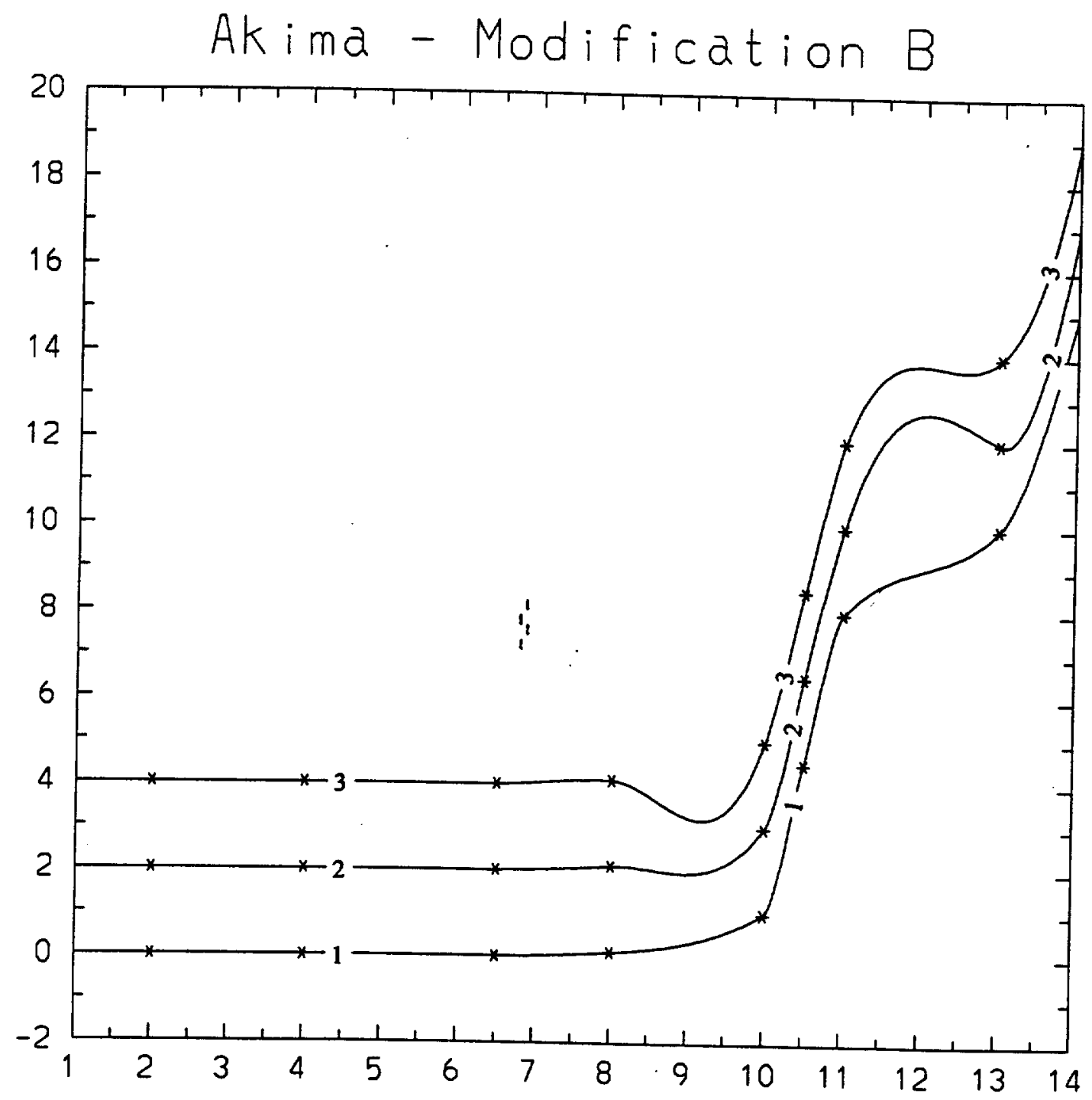

1: PCHIC (default B.C., SWITCH $=-1$ )

2: Algor ithm 697

3: Algorithm 514 
Fig. 9

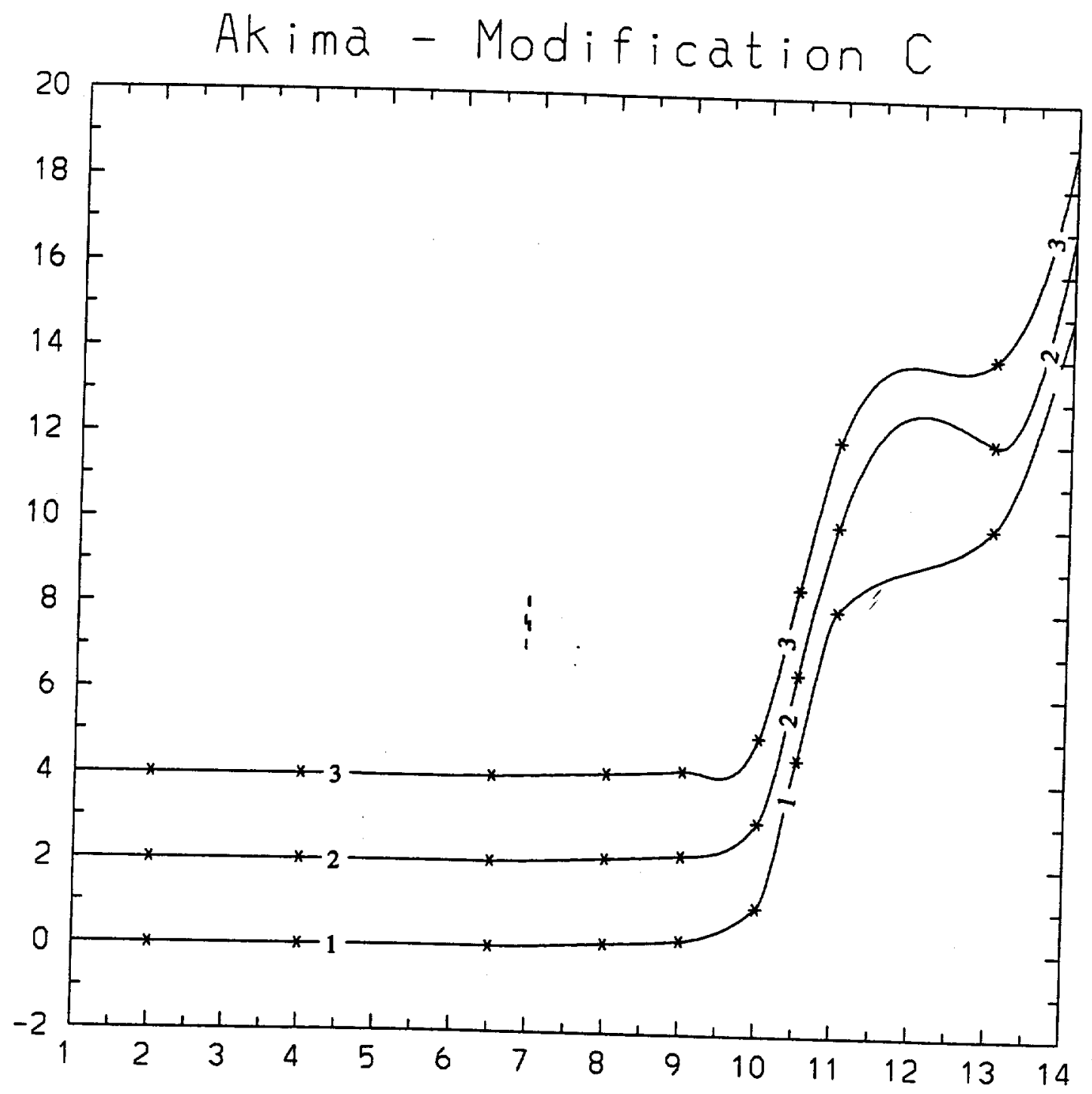

1: PCHIC (default B.C., SWITCH=-1)

2: Algorithm 697

3: Algor ithm 514 
Fig. 10

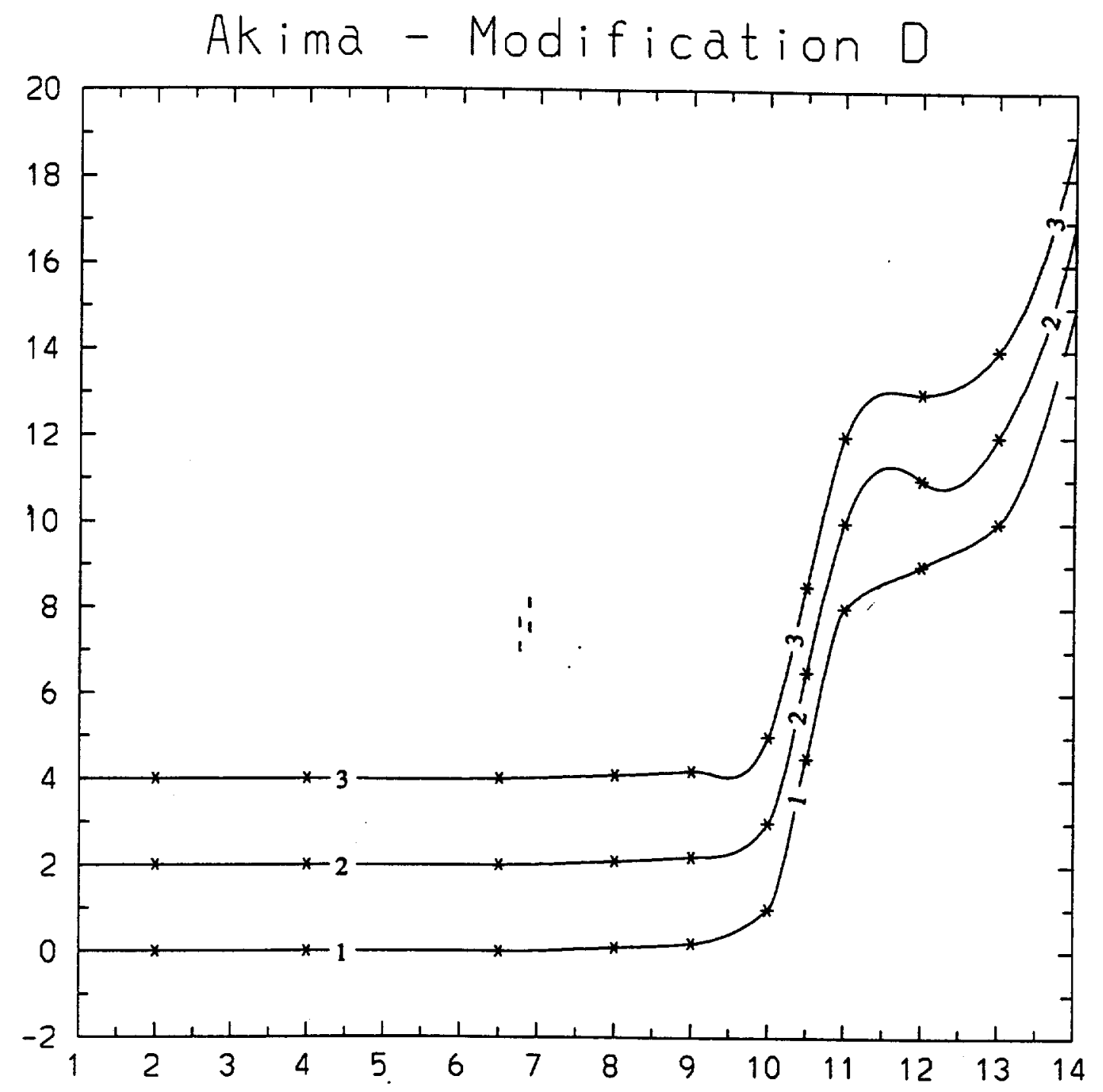

1: PCHIC (default, B.C., SWITCH=-1)

2: Algorithm 697

3: Algorithm 514 
Fig. 11

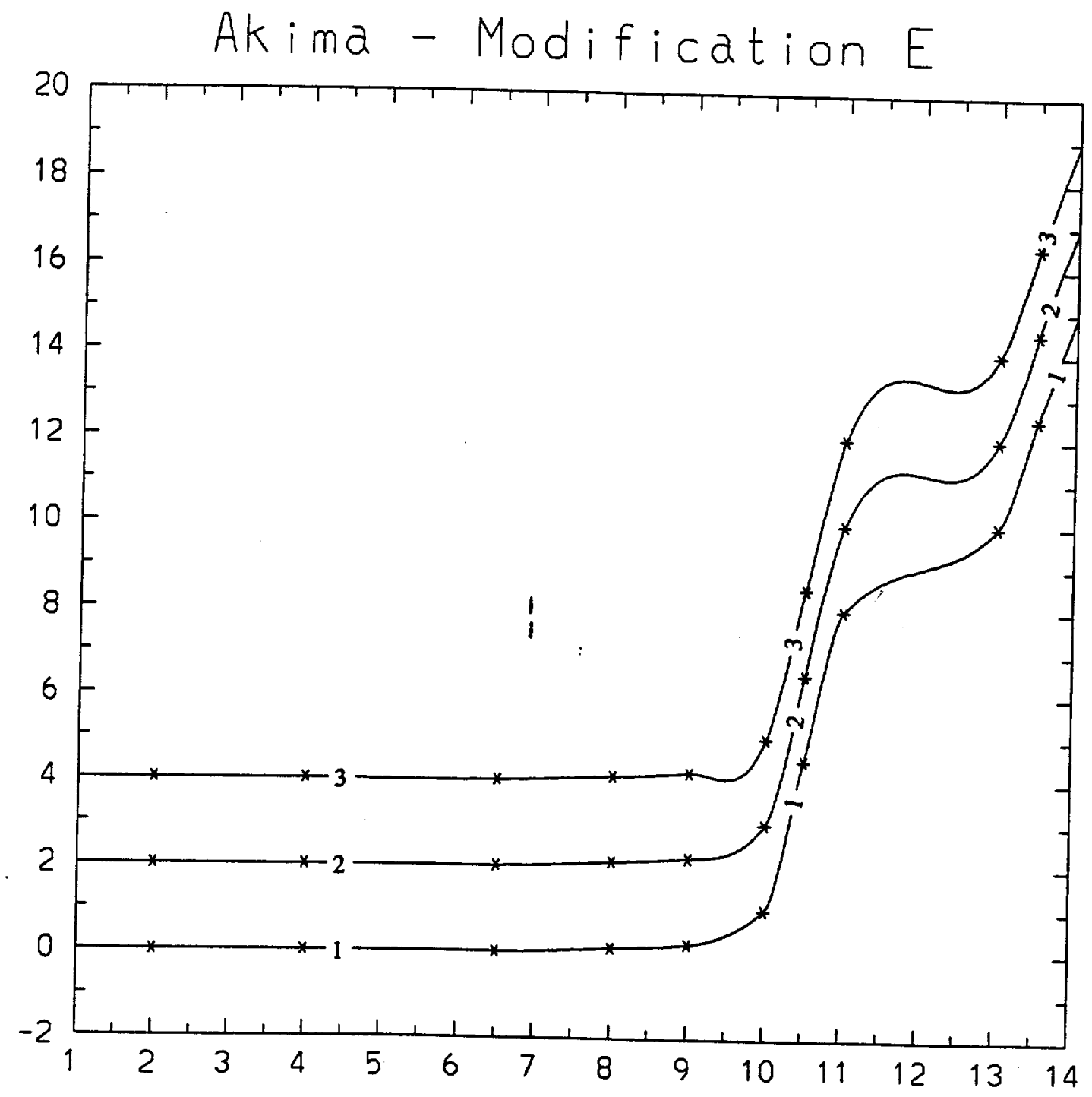

1: PCHIC (default B.C.. SWITCH=-1)

2: Algorithm 697

3: Algorithm 514 


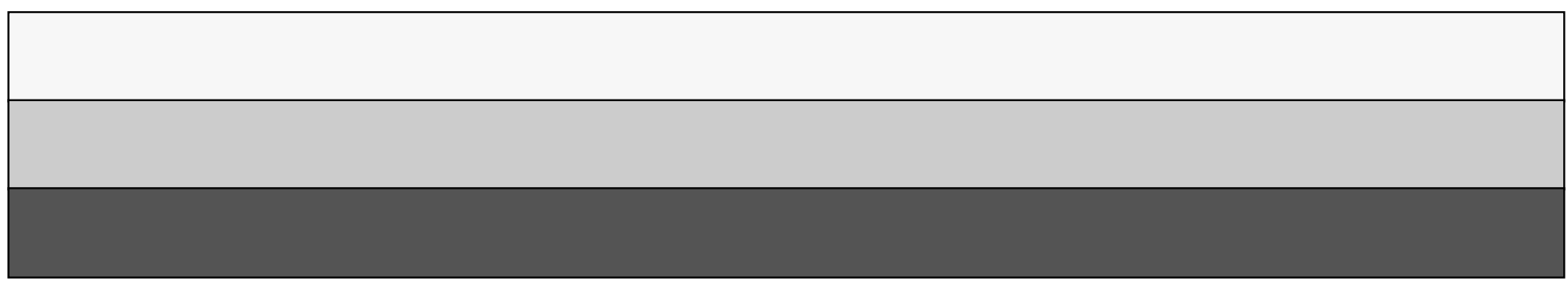

